\title{
Benefits and challenges of automated materials technology in industrial construction projects
}

Vineeth Dharmapalan PMP

PhD candidate, Department of Civil, Architectural and Environmental Engineering, The University of Texas at Austin, Austin, TX, USA

(corresponding author: vineeth.dp@utexas.edu)

(Orcid:0000-0003-1235-460X)

\author{
William J. O'Brien PhD \\ Professor, Department of Civil, Architectural and Environmental \\ Engineering, The University of Texas at Austin, Austin, TX, USA \\ (Orcid:0000-0002-3366-3201)
}

The widespread adoption of automated materials locating and tracking technologies (AMLTTs) in the construction supply chain can positively impact productivity in industrial construction projects. Prior academic studies have identified the need, recommended the use and demonstrated the potential of AMLTTs using field trials and experiments. These studies have also identified the potential benefits and challenges of AMLTT implementation. Very few studies have empirically examined the on-site application of AMLTTs in projects and reported the actual benefits and challenges. This paper examines the commercial implementation of AMLTT in seven industrial projects to examine the benefits and challenges. Based on the empirical studies, four propositions are presented on the benefits and challenges of AMLTT use. First, improved operational efficiency due to AMLTT allows project/firm personnel to focus more on business-critical activities. Second, AMLTT use improves the transactional visibility of materials through information sharing in the supply-chain network. Third, AMLTT use requires a thorough data management plan. Finally, in order to achieve strategic benefits, AMLTT use requires addressing the organisational aspects of technology adoption. The enhanced understanding of the benefits and challenges of AMLTT implementation is the contribution to the industrial construction body of knowledge.

\section{Introduction}

Project materials play a vital role in the success of an industrial construction project. Out of the total cost of a construction project, $50-60 \%$ is attributed to the cost of construction materials (CII, 1988; Stukhart and Bell, 1986). It is also estimated that materials control $80 \%$ of the project schedule (Kerridge, 1987). Inappropriate materials management causes a shortage of materials due to materials getting lost or damaged, required materials not being purchased, purchased materials not getting delivered, errors in material take-offs and materials issued to craftworkers not used or installed (CII, 1988). Traditional manual processes of information exchange and processing further compound the issues related to poor materials management (Vorster and Lucko, 2002). These include inaccurate warehouse records, improper storage, improperly sequenced deliveries and large surpluses of materials (Thomas et al., 2005). All these factors contribute to low craft productivity, cost overruns, idle time, delays in construction and inefficient planning and execution (Kaming et al., 1998).

The advent of automated information systems and wireless and display technologies is now providing opportunities to use digital information for project delivery and asset management processes (Vorster and Lucko, 2002). One body of academic research has focused on devising strategies specifically around the use of automated materials locating and tracking technologies (AMLTTs) to make materials management more efficient (Young et al., 2011). AMLTTs include radio-frequency identification (RFID), barcodes, global positioning system (GPS), geographical information systems, mobile user interface devices, sensors and the Internet, which can be utilised to track and trace materials in the supply chain and construction site (Wood and Alvarez, 2005). Studies have conducted prototype development and testing of these technologies in field application environments (Aksoy et al., 2004; Caldas et al., 2004). Further, they have also documented the expected benefits and challenges based on the implementation of these technologies (Caldas et al., 2006; Song et al., 2006a).

Over the past decade, the industrial construction sector began utilising AMLTT on projects (Young et al., 2011). However, the implementation of AMLTT on-site has been limited ( $\mathrm{Li}$ et al., 2016) despite the expected benefits highlighted by the literature. One of the reasons for limited adoption has been attributed to the fact that the majority of the studies on AMLTT have been technical feasibility studies using trials and field experiments and not based on on-site applications ( $\mathrm{Li}$ et al., 2016). Furthermore, most of them were conducted during the late 1900s and early 2000s. Therefore, there is limited up-to-date knowledge based on the commercial on-site application of AMLTTs on projects.

This study explores the on-site commercial implementation of AMLTTs in seven case studies to emphasise or extend benefits and challenges reported in previous research. This paper is organised as follows: first, the relevant literature on AMLTT is reviewed. This is followed by a description of the research methodology. Next, key empirical findings are presented as propositions. Finally, the paper ends with the discussion and conclusions of the study. 


\section{Literature review}

The literature review of AMLTTs focused on technologies used for construction material identification, locating and tracking. The development of these technologies and associated benefits and challenges are presented in this section.

\subsection{AMLTT development}

Authors have examined the use of AMLTT in the field of construction since the late 1980s. In 1987, the Construction Industry Institute funded a formal research project to explore potential applications and the status of auto-identification technology use in the construction industry. It was one of the first studies that found that construction companies utilised barcode technology for field material control and warehouse inventory management (Bell and McCullouch, 1988). After that, the authors began testing the feasibility of barcodes with construction information management applications (Rasdorf and Herbert, 1990). In time, more efficient and reliable technologies such as two-dimensional barcodes and RFID were identified for construction materials management. One of the seminal works that reported the potential use of RFID for materials control in construction was by Jaselskis et al. (1995). RFID systems can be either passive or active, depending on the power source, cost, range and complexity. For instance, Jaselskis and El-Misalami (2003) used passive RFID tags and handheld readers to track the receiving process of pipe spool supports and hangers in laydown yards of two job sites. Song et al. (2006b) examined the feasibility of automating the delivery (shipment verification) and receiving the process of pipe spools using active RFID tags. In addition to manual scanning using handheld readers, readers were installed on the portal gates. Flatbed trailers loaded with the pipe spools passed through these portal gates, thereby populating the spool delivery and receipt information. Studies have also investigated ways to improve the locating process of construction materials in huge laydown yards. Caldas et al. (2006) tested the potential of GPS and handheld computers in the pipelocating process on an industrial project. The technologies were integrated to automate the pipe spool receiving, storing and issuing operations in laydown yards.

Researchers have also integrated multiple technologies to provide additional material information and enable a streamlined flow across project phases (Valero and Adán, 2016). Torrent and Caldas (2009) proposed a methodology for combining RFID and GPS technologies to automate the identification and localisation of construction components in industrial projects. The process involves attaching active RFID tags to individual materials and securing a couple of RFID and GPS receivers to a piece of roving equipment (mobile cranes, forklifts or vehicles). The RFID technology in the integrated system performs the identification and monitoring of materials. The GPS technology tracks the location and position of the material and the identification and location information from the RFID readers. The roving equipment would be used for data collection purposes. Recently, authors have also started testing unmanned vehicles fitted with RFID readers to identify and locate construction materials tagged with RFID in laydown yards (Irizarry and Costa, 2016).
Studies of material tracking using technologies have been conducted at off-site fabrication plants and in the supply chain. For instance, Ergen et al. (2007) used RFID and GPS to track status and location information for the management of precast components, pipe spools and fire valves. In comparison with the other studies, this research used a wireless local area network to transmit information regarding the three engineered components in manufacturing plants, storage yards (off-site and on-site), construction sites and facilities. Ultra-wideband, ZigBee, Bluetooth, wireless fidelity (Wi-Fi) and embedded sensor systems are examples of different wireless sensor network technologies that have been investigated and used in locating and tracking materials ( $\mathrm{Li}$ and Becerik-Gerber, 2011). These communication networks enable transfer and exchange of information between sensors and mobile and fixed devices.

In addition to standalone devices and multi-technology combinations, more recent literature focuses on investigating the potential of a network of interacting technologies. The argument is that the aforementioned solutions only offer suboptimal deployment and result in marginal improvements. The approach, known as cyber-physical systems (CPSs), integrates the bidirectional coordination between virtual prototypes (using threedimensional/four-dimensional computer-aided design models of proposed facilities) and the physical construction (and associated monitoring using sensing technologies) (Anumba et al. 2010). Furthermore, digital twins (DTs) - a subset and emerging form of CPS - are claimed to have significant potential to transform the construction industry. DTs are a near-real-time replica of a physical facility or process and include all the information useful throughout the life-cycle phases (Kan and Anumba, 2019). Numerous benefits are expected as a result of these technologies. These include transparency and collaboration across project participants, better data interoperability, real-time monitoring and information sharing and accurate decision-making through accurate performance prediction (Anumba et al., 2010).

\subsection{AMLTT benefits and challenges}

Prior research has claimed that AMLTT offers a plethora of benefits. Bell and Stukhart (1987) stated that foremen lost $20 \%$ of their working time searching for materials and another $10 \%$ tracking purchase orders and expediting. For example, it took approximately $7 \mathrm{~min}$ on average to locate a pipe spool in a construction laydown yard (Caldas et al., 2006). In the study by Caldas et al. (2006), the same spool was located in less than a minute using GPS technology. Similarly, Jaselskis and El-Misalami (2003) found that the time taken for the material-receiving process using passive RFID technology was less than that using the manual method. Reduction in the number of lost items, positive schedule impact, process improvement, enhanced data entry and route and layout optimisation were some of the other potential benefits identified by the study (Caldas et al., 2006). Song et al. (2006b) and Grau et al. (2012) used active and passive RFID tags, respectively, to track the flow of engineering components during the shipping and receiving process. In addition to the reduction in 
search time, the other benefits included improved accuracy of shipping, receiving and inventory information. The ability to provide timely and accurate information on materials availability increased schedule reliability and presented potential for improved labour performance. Grau et al. (2009) examined the impact of RFID and GPS technologies on craft productivity. The study compared the traditional and automated tracking procedures of structural steel components. Savings in installation time, improved predictability of finding items and potential for process reengineering were some of the benefits reported by the study. The potential of AMLTT to increase visibility within the construction supply network was identified by Young et al. (2011). Using a simulation study of the fabrication and installation of pipe spools, the authors demonstrated that the system is capable of improving schedule performance, reducing uncertainty and limiting reliance on material buffers.

To the best of the authors' knowledge, the industrial sector literature on AMLTT primarily focuses on technical limitations or disadvantages (Akinci et al., 2004; Song et al., 2004). This can be attributed to the nature of the studies. For example, Li et al. (2016) reviewed 75 articles from five journals on AMLTT and found that over $50 \%$ of them are related to field-trial experiments and AMLTTs had not been fully implemented in real construction projects. Considering the dearth of studies on the implementation challenges of AMLTT in industrial construction, the authors expanded the scope of their review to include general information and communication technologies (ICTs) and AMLTT challenges on non-industrial projects. For example, Sardroud (2015) reviewed challenges to ICT and identified 19 challenges specific to the adoption of AMLTT in the construction industry. The 19 challenges were categorised into four clusters - namely, costrelated factors, process-related factors, technology-related factors and others. Lack of standards, the return-of-investment uncertainty, deployment and maintenance costs, top management buy-in and lack of implementation process knowledge are some of the challenges that were identified in the study. Erdogan et al. (2008) studied the implementation of collaboration tools and systems in construction using literature review and case studies. The authors found that the investigated cases failed to tap into the full benefits of collaborative systems since they prioritised the technical issues of the systems and ignored the people and organisational issues. The importance of addressing people issues associated with technology implementation was also posited by O'Brien (2000). The author gave a practitioner's viewpoint on the challenges regarding the implementation of project websites in the construction industry. Kang et al. (2012) explored the factors driving and hindering the implementation of integration opportunity tools in the industrial sector. The authors evaluated organisational and people-related issues that hindered the implementation of the tool.

\section{Point of departure and research objective}

Most of the academic research works on AMLTT were experimental studies carried out off-site (Li et al., 2016). Very few studies investigated the on-site application of these technologies on real construction projects (Sardroud, 2015). The ones that did were limited to field-trial experiments using technology prototypes (Grau et al., 2009; Razavi and Haas, 2011; Torrent and Caldas, 2009). Additionally, since these studies were primarily technical feasibility studies or individual experiments (Akinci et al., 2004; Caldas et al., 2006; Song et al., 2004), expected benefits and technical challenges of AMLTT were reported. Some authors (Erdogan et al., 2008; O’Brien, 2000) argued that giving priority to technical challenges by undermining implementation challenges limits companies from taking full advantage of the benefits of technology deployment. It is, therefore, essential to confirm if the expected benefits and challenges are observed in a real construction environment.

Recent studies are beginning to report the implementation of AMLTT on projects (Young et al., 2011). However, up-to-date knowledge of actual implementation benefits (Ko et al., 2016) based on the routine commercial on-site application of AMLTT on projects is limited. The only exception is a study by $\mathrm{Li}$ and Becerik-Gerber (2011), who examined a decades-long implementation of technology in the construction industry by reviewing academic papers and industry use cases. The authors examined the interaction between academia and industry concerning technology implementation and suggested approaches to increasing the adoption of technology in the industry. However, the study only focused on RFID technology and reviewed online articles for industry use cases. Sardroud (2015) found that inadequate evidence of success in real construction projects precludes full investment in technology. An empirical examination of AMLTT application on actual construction projects can provide valuable insights to increase industry adoption and to advance research in the area.

The objective of this study is to investigate the on-site application of AMLTT on industrial projects to emphasise or extend the existing literature concerning the benefits and challenges of AMLTT implementation. The confirmation (or extension) of the expected benefits and challenges due to on-site AMLTT implementation will encourage industry adoption and future research and development.

\section{Methodology}

A qualitative research method was deemed more appropriate due to the confirmatory nature of the study (Yin, 2009). The case study method was selected since the objective of the study was to gain more insights into AMLTT implementation in practice and particularly to explore the benefits and challenges of AMLTT implementation. The appropriate units of analysis for this study were construction projects. The construction projects were selected using the purposive sampling approach (Lincoln and Guba, 1985). Specifically, the approach involved project selection using the following criteria: (a) the sample included multiple relatively unique but analytically similar cases that have depth; (b) including projects that have adopted or are utilising AMLTT; 
and $(c)$ the projects were either $100 \%$ completed or nearing completion These efforts helped in understanding the project characteristics that led to the deployment of specific AMLTTs. It also contributed to replication logic, used to bolster evidence by repetition and to improve generalisation (Eisenhardt, 1989). The selected sample of projects included industrial projects from different sectors (oil and gas, power, mining and metals) and portfolio (offshore, onshore, distribution). The projects also varied in terms of level (on-site laydown yard, on-site and off-site laydown yard, multiple nodes of the supply chain) and scope (just pipe spools, engineered materials, all materials) of AMLTT deployment. This approach of investigating multiple cases with different conditions enhanced the external validity of the research design (Slaughter et al., 2006).

An interview schedule was created, and interviews were conducted with the project personnel of the respective projects using a semi-structured interview guide. The case study questions are included in the Appendix. To ensure construct validity, the guide was sent to the interviewees beforehand to enable them to acquire the necessary knowledge about the topics to be covered. Adjustments were made to the guide after the initial round of interviews. In order to ensure uniformity and consistency in data collection, the research investigator used the same interview guide in all interviews. To improve the internal validity of the findings, efforts were made to interview multiple sources within the same project. Interviewing multiple respondents also supported the source triangulation of the data (Lincoln and Guba, 1985).

The data from the interviews were analysed at two levels: withincase and across-case analyses. For within-case analysis of each case, extensive notes were taken and detailed case study write-ups were generated. This process helped in managing the analysis of the large volume of data, generation of insights and the emergence of unique patterns from each case (Eisenhardt, 1989). The analysis of each case contained a detailed description of the AMLTT application in the supply chain considering the project context, including the process description, type of technology used, reported benefits and challenges. Project documents, field observation cards, process flow diagrams, demonstration of the AMLTT software system, on-site observation of the AMLTT process and the material transaction database generated by the AMLTT system were the additional sources of data that were reviewed. The detailed write-ups were returned to the interviewees for verification. The verification of the case study write-ups by the interviewees and the multiple sources of evidence supported data triangulation and construct validity (Eisenhardt, 1989; Yin, 2009).

Next, the research team performed a cross-case analysis to generalise patterns across cases. The authors analysed the individual cases, added their impressions, aggregated findings and developed preliminary propositions. Both the authors then exchanged their respective analyses with each other for review. The pattern search was assisted by conducting across-case analysis in two dimensions, using the recorded benefits and challenges of AMLTT. This was followed by searching for within-group similarities and across-group differences. The observed patterns facilitated in drawing inferences regarding AMLTT implementation in industrial construction. Finally, sets of inferences were used as themes and further developed into propositions.

\section{Case studies}

A total of seven projects were investigated to reach a stage where no new line of thinking emerged from the investigations. Table 1 provides an overview of the key characteristics of the investigated projects and the corresponding interviews conducted. A total of 14 interviews were conducted across the seven projects. The number of interviews per project ranged from one to four, and each interview lasted between 30 and $90 \mathrm{~min}$. The project names were coded P1 through P7 for confidentiality. The technologies under AMLTT used on the seven projects are summarised in Table 2, and the scope of AMLTT implementation (materials tagged using AMLTT and location of tagging) on each project is summarised in Table 3. The seven projects, their scope and year, the context that led to AMLTT implementation, AMLTTs used and the implementation process are described next.

\subsection{Project P1}

Project P1 in the north-central part of the USA investigated a brownfield project in the power sector. The project was chosen since it is one of the first industrial construction projects to implement AMLTT. Also, the AMLTT system was used as a point solution, to identify and locate materials in the on-site project laydown yards. The project involved the expansion of an existing power plant by constructing two coal-fired, steam-turbine generating units and related civil works to produce approximately $1230 \mathrm{MW}$ of electricity. The construction started in 2005 with a commercial operation of unit 1 in 2010 and of unit 2 in 2011. The state energy division was the owner of the project and had a lumpsum contract with the engineering-procurement-construction (EPC). The EPC self-performed the work by directly hiring craftworkers and had in-house materials management and an inventory management team for laydown/warehouses.

Labour cost saving, the large number of materials that were required to be managed and weather conditions were the major drivers that led to the decision to implement AMLTT on the project. The EPC controlled all the money for the project since it had a lump-sum contract with the owner. The EPC recognised the need to save on direct labour that they hired for receiving, locating and issuing materials using the conventional paper-based method. Moreover, a large number of materials had to be managed manually. The owner provided the EPC firm with old farmlands (cornfields and hayfields) for storing materials. The EPC also had the freedom to develop laydown space as required during the project. Ultimately, the EPC had six laydown yards onsite and two off-site warehouses. The ample storage space for materials resulted in the majority of the construction materials 
Table 1. Overview of project characteristics and conducted interviews

\begin{tabular}{|c|c|c|c|c|c|c|c|}
\hline $\begin{array}{l}\text { Project } \\
\text { number }\end{array}$ & $\begin{array}{l}\text { Project } \\
\text { type }\end{array}$ & Sector (portfolio) & Location & $\begin{array}{l}\text { Contract } \\
\text { type }\end{array}$ & Interview title & $\begin{array}{l}\text { Company } \\
\text { category }\end{array}$ & $\begin{array}{l}\text { Additional } \\
\text { data source }\end{array}$ \\
\hline P1 & Brownfield & Power & USA & $\begin{array}{l}\text { Lump- } \\
\text { sum }\end{array}$ & Materials manager & Contractor & $\begin{array}{l}\text { Field } \\
\text { observation } \\
\text { cards }\end{array}$ \\
\hline P2 & Greenfield & $\begin{array}{l}\text { Oil and gas (onshore } \\
\text { exploration) }\end{array}$ & Canada & $\begin{array}{l}\text { Time and } \\
\text { material }\end{array}$ & $\begin{array}{l}\text { Materials manager } \\
\text { Field procurement } \\
\text { manager } \\
\text { Materials control manager }\end{array}$ & $\begin{array}{l}\text { Owner } \\
\text { Contractor } \\
\text { Subcontractor }\end{array}$ & $\begin{array}{l}\text { Field } \\
\text { observation } \\
\text { cards; } \\
\text { software } \\
\text { demonstration }\end{array}$ \\
\hline P3 & Greenfield & $\begin{array}{l}\text { Oil and gas (onshore } \\
\text { exploration) }\end{array}$ & Canada & Cost-plus & $\begin{array}{l}\text { Supply-chain manager } \\
\text { Programme manager }\end{array}$ & $\begin{array}{l}\text { Owner } \\
\text { Owner's } \\
\text { representative }\end{array}$ & $\begin{array}{l}\text { AMLTT } \\
\text { database; } \\
\text { software } \\
\text { demonstration }\end{array}$ \\
\hline P4 & Greenfield & $\begin{array}{l}\text { Oil and gas (offshore } \\
\text { exploration) }\end{array}$ & USA & Item rate & $\begin{array}{l}\text { RFID coordinator } \\
\text { Preservation and } \\
\text { maintenance lead }\end{array}$ & $\begin{array}{l}\text { Contractor } \\
\text { Contractor }\end{array}$ & $\begin{array}{l}\text { Field } \\
\text { observation } \\
\text { cards }\end{array}$ \\
\hline P5 & Brownfield & $\begin{array}{l}\text { Oil and gas (distribution - } \\
\text { liquefied natural qas facility) }\end{array}$ & USA & $\begin{array}{l}\text { Lump- } \\
\text { sum }\end{array}$ & Operations manager & Contractor & $\begin{array}{l}\text { Project } \\
\text { documents }\end{array}$ \\
\hline P6 & Greenfield & $\begin{array}{l}\text { Oil and gas (refinery - } \\
\text { petrochemical) }\end{array}$ & USA & $\begin{array}{l}\text { Lump- } \\
\text { sum }\end{array}$ & $\begin{array}{l}\text { Procurement manager } \\
\text { Procurement general } \\
\text { foreman } \\
\text { Construction general } \\
\text { foreman } \\
\text { Laydown yard general } \\
\text { foreman }\end{array}$ & $\begin{array}{l}\text { Contractor } \\
\text { Contractor } \\
\text { Contractor } \\
\text { Contractor }\end{array}$ & $\begin{array}{l}\text { Site } \\
\text { observation; } \\
\text { software } \\
\text { demonstration }\end{array}$ \\
\hline P7 & Greenfield & $\begin{array}{l}\text { Mining and metals } \\
\text { (cement plant) }\end{array}$ & Canada & Cost-plus & Materials manager & $\begin{array}{l}\text { Consultant } \\
\text { (owner's } \\
\text { representative) }\end{array}$ & $\begin{array}{l}\text { Process flow } \\
\text { diagram }\end{array}$ \\
\hline
\end{tabular}

being sent to the site ahead of construction. Finally, the challenge of managing large amounts of materials on the project was compounded by the extreme weather conditions in the state. In fact, the project had to be fast-tracked since the project was 100 million over budget due to weather-related delays. The EPC had to work in double shifts and round the clock to make up the schedule.

The EPC's materials manager championed the use of the AMLTT system on the project. The EPC firm was figuring out process improvement techniques using Six Sigma during the time. The materials manager felt that the project context was ideal for the implementation of an RFID-based system. The technology was

Table 2. AMLTT usage on the projects

\begin{tabular}{|c|c|c|c|c|c|c|c|}
\hline \multirow{2}{*}{ Technologies } & \multicolumn{7}{|c|}{ Project } \\
\hline & P1 & P2 & P3 & P4 & P5 & P6 & P7 \\
\hline Barcodes & & & $\checkmark$ & $\checkmark$ & & & $\checkmark$ \\
\hline Passive RFID tags & & & & $\checkmark$ & & & \\
\hline Active RFID tags & $\sqrt{ }$ & $\checkmark$ & $\checkmark$ & $\checkmark$ & $\checkmark$ & $\checkmark$ & $\checkmark$ \\
\hline $\begin{array}{l}\text { Mobile tablets with } \\
\text { barcode/RFID readers }\end{array}$ & $\checkmark$ & $\checkmark$ & $\checkmark$ & $\checkmark$ & $\checkmark$ & $\checkmark$ & $\checkmark$ \\
\hline Gate reader (off-site) & & $\checkmark$ & $\sqrt{ }$ & & $\checkmark$ & & \\
\hline Gate reader (on-site) & & $\checkmark$ & $\checkmark$ & & $\checkmark$ & $\checkmark$ & \\
\hline Vehicle-mounted readers (off-site) & & $\checkmark$ & & & $\checkmark$ & & \\
\hline Vehicle-mounted readers (on-site) & & $\checkmark$ & & $\checkmark$ & & & \\
\hline Web-based server application & $\checkmark$ & $\checkmark$ & $\checkmark$ & $\checkmark$ & $\checkmark$ & $\checkmark$ & $\checkmark$ \\
\hline
\end{tabular}

unproven and brand new to the EPC environment. The materials manager had to convince the top management, and after 1 year of construction, the top management supported the decision.

The process was used to identify and locate pipe spools and structural steel. Both the materials were tagged using active RFID tags once they arrived on the job site and subsequently stored in laydown yards. During construction, the mobile tablets equipped with RFID readers were used to locate the tagged materials that were to be issued for construction.

Table 3. Materials and corresponding tagging location on the projects

\begin{tabular}{|c|c|c|}
\hline \multirow{2}{*}{ Materials } & \multicolumn{2}{|c|}{ Tagging location } \\
\hline & Off-site ${ }^{a}$ & On-site ${ }^{b}$ \\
\hline Pipe spools & $P 2, P 5, P 6$ & P1, P4 \\
\hline Structural steel & & P1 \\
\hline Cable reels & P2 & P6 \\
\hline Pipe supports & & P4 \\
\hline Valves and instrumentation & P2 & \\
\hline Equipment & P2 & \\
\hline Ship-loose items ${ }^{c}$ & & P2 \\
\hline All materials & P3 & P7 \\
\hline
\end{tabular}




\subsection{Project P2}

Project P2 was an in situ project in Canada and estimated to produce approximately 90000 barrels $\left(1.43 \times 10^{4} \mathrm{~m}^{3}\right)$ per day. The owner of the project awarded the prime contractor or EPC with the front-end engineering activities (FEL-3) in 2008 and the EPC phase for the entire project in 2010. The scope of work included the central processing facilities and the area of the field facilities consisting of nine wall pads. The EPC had to provide modules and erect them on-site. Unlike project P1, the EPC of project $\mathrm{P} 2$ had subcontracted the materials management effort. Also, for additional control and efficiency in fabrication, the EPC fabricated pipe spools within their own family of companies and transported them to a modular yard that was 270 miles $(435 \mathrm{~km})$ from the project site.

As in project P1, the need for AMLTT in project P2 was largely driven by the number of materials, weather conditions (snowfall for 6 months a year) and high labour costs in Canada. However, in the case of project P2, the economic downturn in 2008 significantly impacted the project. At the time of procurement strategy, the market was at its peak (lots of projects in progress, high factory utilisation). To avoid disruption during construction, it was necessary to have an assurance of a constant supply of materials to the site. Therefore, it was decided to have the materials in production and store them. However, the economy changed midway, and construction could not keep pace with production, resulting in an abundance of an unused inventory of materials on-site since suppliers/fabricators could not hold on to the materials beyond a specific time frame. To hold the additional inventory onsite, the project needed approximately 130000 square feet $\left(\mathrm{ft}^{2}\right)$ $\left(1.21 \times 10^{4} \mathrm{~m}^{2}\right)$ of laydown space. However, they ended up getting $15000 \mathrm{ft}^{2}\left(1.39 \times 10^{3} \mathrm{~m}^{2}\right)$ of laydown space 200 miles $(322 \mathrm{~km})$ from the project site. Moreover, the owner discovered a lack of sizeable off-site storage space during the project and thus had to rent multiple smaller-sized laydown yards. Ultimately, due to the termination of the rental agreements, the materials had to be stored in over 150 trailers for 5 months on the project site.

As in project P1, the implementation of the AMLTT system was initiated by the EPC. It was this EPC's (project P2) sister company that had pilot-tested the use of RFID-based technology in project $\mathrm{P} 1$. Based on the good results witnessed in project $\mathrm{P} 1$, the system was implemented in project P2 to track pipe spools, cable reels and instrumentation. However, in addition to on-site project laydown yards (project P1), the system was also used at the EPC's pipe spool fabrication facilities in project P2. The use of gate readers to document incoming materials and vehiclemounted readers (VMRs) to update inventory information was the other exception in comparison with project $\mathrm{P} 1$.

\subsection{Project P3}

Project P3 is an oil and gas project in Canada to boost output in the region by approximately 180000 barrels $\left(2 \cdot 86 \times 10^{4} \mathrm{~m}^{3}\right)$ per day. This project was shelved due to the financial crisis of 2008 . Ultimately, it was started in 2014, fast-tracked and concluded in
2018. The project involved the mining and extraction process of bitumen. The scope of work included mine and site development, ore preparation plant, extraction and tailing and froth treatment facilities. As in project P2, a modular construction approach was utilised in project P3. The fabrication of steel and pipes was conducted in multiple plants based in Asia. The supply chain of project P3 included multiple international off-site fabrication facilities, ports, a central staging yard and modular yards managed by multiple contractors and the project laydown yard. Project P3 was chosen for the study, as it is an example of the inter-site application of an AMLTT system, including logistics and traceability components.

The owner was the champion and initiated the implementation of AMLTT on the project. In fact, the owner mandated the use of the system in the contract. The EPC was an international firm based in Asia with no prior experience of working in Canada. The EPC's lack of experience in Canada, high labour rates, fast-tracking and weather were the major drivers that led to the owner to mandate the use of the system on the project. Additionally, the owner had prior experience with the technology on a previous project. As a result, the owner implemented the AMLTT system from the beginning of the project in 2014. It also led to the adoption, utilisation and compliance of the system and process by the other project participants (EPC, subcontractors and fabricators). All materials were tracked using active RFID tags and barcodes on the project. However, the location of the tagging of materials varied; structural steel and pipe spools were tagged at fabrication facilities, while some vendor-supplied materials were tagged at the time of arrival on-site. Steel and pipe spools from the Asian-based fabricators were part of the modular assembly programme for the project-fabricated steel, and pipes from Asia were loaded onto skids by a module work package. These skids were transferred into containers and shipped to a centralised staging yard in Canada. Four modular yards next to the staging yard requested materials based on the work package corresponding to the skid numbers. The skids were then transferred to the modular yards for assembly of modules. The modules once completed were shipped to the site for installation. Gate readers and mobile tablets with RFID/barcode readers were used at the fabrication facilities, central staging yard and modular yards. The supply-chain manager utilised a dynamic simulation model to plan the module programme for the project. Tactical planning for supply chain and logistics operations, module supply, inventory and capacity planning were performed using the simulation model.

\subsection{Project P4}

For project $\mathrm{P} 4$, the case study investigated a module facility with work for multiple projects running simultaneously. Project P4 was chosen since it offered a unique example of a multi-project facility. The facility fabricated and constructed the topsides of offshore semi-submersible platform rigs for oil and gas producers operating in the Gulf of Mexico. The 'topside' modules consisted of power, utility, equipment and living quarters. The materials that go into the facility are plates, pipes, pipe supports, process cables, 
cable trays, instrumentation and engineered equipment. Once completed, these modules are pushed onto a barge, lifted and set on the hull for integration.

The contractor (fabricator and constructor) of the platforms initiated the implementation of the AMLTT system. Specifically, a warehouse superintendent of the firm was responsible for championing the system since 2011, after observing inefficiencies in tracking assets using spreadsheets and paper-based systems. The multi-project environment and associated large amount of materials in topside construction were the major drivers of the implementation of AMLTT. Pipe spools and pipe supports built by the firm in their fabrication shops are tracked using RFID and stored in the laydown yard. Active RFID is used for pipe spools, while passive RFID is used for pipe supports. Field engineers from the topside installation site would request spools and supports by work area (the deck of a topside is divided into quadrants). The inventory management team would load trailers with the work order and deliver it to the quadrant at the deck or to the lead that is responsible for the installation work. Mobile tablet readers and VMRs were used for monitoring and for updating materials in the inventory in the laydown yard.

\subsection{Project P5}

The investigated P5 was an ongoing 5.25 Mt per annum liquefied natural gas (LNG) facility in the USA that will condense liquid gas for export. The facility, combined with the existing facility, will provide a bidirectional service of import and export of LNG at the terminal. The owner of the facility awarded the contract to the prime contractor in 2013, and the project was completed on schedule in 2018.

The EPC had utilised the AMLTT system on past projects and was cognisant of the benefits. The drivers for the use of the system on the project were the number of logistics between locations and the complexity of operations involved in the project. The process was used to identify and locate pipe spools. Two fabricators of pipe spools had laydown yards in their facilities as per contract, and tagging of the spools using active RFID was performed at their facility post-fabrication and painting. These two fabrication facilities were in a different state of the country. Gate readers were installed at each fabrication laydown yard to track the exit information of the spools. Two smaller off-site project laydown yards near the job site (1 mile $(1.61 \mathrm{~km})$ away) were leased out by the EPC. These off-site project laydown yards, too, had gate readers to track the material movement. These offsite project laydown yards were 800 miles $(1290 \mathrm{~km})$ away by road from the two fabrication facilities.

There was a lack of storage space on the project site, and hence, a near-just-in-time process had to be followed for the project. First, field engineers on-site would request for materials from off-site project laydown yards. The off-site laydown crew would locate and load the tagged spools that were received from the fabrication yards (based on the work package and $30 \mathrm{~d}$ lookahead) onto flatbed trailers. These trailers were also tagged with active RFID since trailers had to be loaded based on work packages. The field crew would be communicated about the trailer number that needed to be opened for the specific work package. The trucking company just had $48 \mathrm{~h}$ to load, transport, drop the loaded trailers and pick the empty trailers from the site.

\subsection{Project P6}

Project P6 was a petrochemical project-ethylene plant constructed to produce medical-grade plastics. The owner had an engineering-procurement contract with an entity that specialised in ethylene plant design. The construction and related procurement were by a large contractor located in North America, having expertise in oil, gas and chemical projects. Once completed, the plant will have a capacity of approximately $1.6 \mathrm{Mt}$ of ethylene per year. The project started in 2014 and was completed in 2018.

As in project P1, the EPC had a lump-sum contract with the owner and championed the AMLTT programme on this project. Also, the EPC had experience with the system and process on past projects (project $\mathrm{P} 2$ ). Being aware of the benefits, the project procurement manager developed a business case to the upper management on the possibility of cost savings by using the technology and process. The programme required 4 months of convincing the top management and integration with the EPC's in-house procurement system. This drove the AMLTT implementation from the beginning of the project. Pipe spools and cable reels were tagged using active RFIDs. The materials were tracked and traced from the fabrication facilities in the Gulf Coast and the Middle East. The materials were tagged at the fabrication facilities post-fabrication. Gate readers installed on-site and mobile tablets with RFID readers were used to track and locate the incoming and stored materials, respectively. The EPC had lump-sum contracts with the fabricators and the subcontractors based on unit rates.

\subsection{Project P7}

Project P7 investigated a cement plant expansion project constructed in Canada to produce $3300 \mathrm{t}$ of cement per day. The project scope included a stacker/reclaimer dome, a preheater tower, a vertical raw mill, an energy-efficient vertical cement mill, a clinker cooler system, a kiln and a blending silo. Although the owner had built similar plants outside Canada, it was in places where land and labour were cheaply available. This was their first project in North America. The owner managed the engineering, procurement and construction of the project by hiring subcontractors for the different work packages. The project was scheduled to start in late 2007. However, as in projects P2 and P3, the economic downturn led to the suspension of the project in late 2008. Unforeseen site conditions and inclement weather led to further delays, and the project finally started in 2013.

Many factors led to the implementation of AMLTT on the project. First, the delayed start of the project meant that an efficient process 
was required to save time and cost. Second, the lack of experience in North America impacted decision-making and consequently affected materials management operations. For example, the economic downturn resulted in the organisation releasing many of its experienced personnel, one who had worked on similar projects outside Canada. However, the new project team failed to conceptualise the supply chain (location and number of laydown yards) and inventory management. The high labour cost, amount of materials that required to be managed and time required for materials management were not considered. As an example, the lack of planning and delay in a decision on having a heated against a nonheated warehouse cost an additional US\$150000, as the materials ended up being stored in five warehouses in different locations.

The owner hired an independent consultant (as an owner's representative) to put the project back on track. The consultant managed the materials and logistics on the project. After observing the inefficiencies and assessment, the consultant convinced the owner of the need for an AMLTT system on the project to avoid potential consequences. The owner obligated the contractors to be on board using contractual terms, mandating the use of the AMLTT system. Except for hardware, all the materials on the project were either barcoded or tagged using active RFIDs. The tagging was performed on the job site once the trucks arrived with a shipment of material. They were then escorted to appropriate warehouses or the laydown yard. The crew used mobile tablets with readers to track and trace inventory at both off-site and on-site project laydown yards.

\section{Findings}

The analysis of the individual cases revealed that the benefits and challenges of AMLTT in the industrial construction context are manifold and are closely related to process changes. Four propositions are developed on the use, benefits and challenges of AMLTT in industrial construction. The contents of the propositions are summarised in the following, and a detailed discussion on the propositions follow. Examples of interviewee perceptions are given for the themes used to develop the four propositions.

- Proposition 1. With improved operational efficiency, AMLTT allows project/firm personnel to focus more on businesscritical activities.

- Proposition 2. The use of AMLTT improves the transactional visibility of materials through information sharing in the construction supply-chain network.

- Proposition 3. The use of AMLTT requires a thorough data management plan.

- Proposition 4. To achieve strategic benefits, the use of AMLTT has to take into account the organisational aspects of AMLTT adoption in projects.

\subsection{Proposition 1: with improved operational efficiency, AMLTT allows project/firm personnel to focus more on business-critical activities}

The adoption of AMLTT enhances the efficiency of operations. These operations include material-level operations such as receiving, locating and issuing materials (Caldas et al., 2006; Grau et al., 2012; Song et al., 2006b). Also, efficient information transfer through AMLTT streamlines logistics operations through route and layout optimisation (Caldas et al., 2004). In the current study, all the seven projects observed a significant improvement in the material receiving, locating and issuing operations. These operations are traditionally very labour-intensive activities, where a large proportion of the field crew's time is spent on non-valueadding activities such as data entry and correction of errors in paperwork (Song et al., 2006b). The problem is bad when an abundant quantity of material is required to be managed and worse if the storage yards are covered in snow.

A similar phenomenon was reported in project P2, where large laydown yards off-site and on-site and the abundant quantity of materials to be managed manually within these facilities were impacting productivity. Furthermore, locating materials in large laydown yards covered in snow for many months a year using the conventional paper-based method was consuming time and resulting in high labour costs. All these factors drove AMLTT implementation on the project. This project also tracked trailers of materials using active RFID tags to improve the visibility of trailers in the staging yard. It helped automate trailer log creation and notifying trailers that are ready for return, thereby minimising carrier's demurrage charges. The materials manager reported that the productive time of the field crew that was previously involved with routine paperwork and material retrieval significantly improved since they could concentrate on their 'time on tools'. Furthermore, the materials manager who was previously engaged fully in materials management operations was able to allocate more time on optimisation and firm-wide implementation of AMLTT. The materials manager described this scenario.

\footnotetext{
The retrieval of spools in laydown yards would have been a challenge without RFID tags. The system supported the evaluation of materials in hand for constructability purposes. It facilitated the biggest cost savings in the retrieval of materials in the snow. My budget came almost a million dollars under due to this system. Most importantly, I was able to roll out the system on multiple projects due to its success.
}

Inefficiencies in logistic operations can be either unavoidable (project P4) or built into the system due to lack of experience (project P7). Four topside projects were going on simultaneously in the same facility. Considering the number of materials for the four projects and the number of logistics required at the facility (between fabrication and construction), the contractor implemented AMLTT at their module facility. The system improved control at the material level for the huge multi-project facility with the faster-locating process using VMRs and tablets, thereby reducing the impact on the schedule and the cost of the four projects. Furthermore, the change due to AMLTT implementation saved labour costs for the facility. The comments of the RFID coordinator on project P4 showed how labour costs for operations were reduced. 
Smart Infrastructure and Construction

Volume 171 Issue 4
Benefits and challenges of automated

materials technology in industrial

construction projects

Dharmapalan and O'Brien
Material locating for all the projects was performed by fitters on site. Fitters have higher wages compared to warehouse staff. The AMLTT system reduced locating times and also construction crew numbers searching for materials. Consequently, the fitters were able to focus on their own trade and time on tools.

Another example of inefficient logistics operation is project P7. The owner's inexperience led to inefficiencies being built into the project since the project team strategised based on construction experience outside Canada - on-site laydown yards far off from the project site $(8$ miles $(12.9 \mathrm{~km}))$ and several small scattered warehouses. The management and tracking of materials would have required double handling and resulted in inefficient logistics operations on the project. AMLTT was able to track and control the amount of inventory dispersed at different locations and mitigate materials management issues. Consequently, the materials management crew could focus on more value-adding tasks than drive between the separate storage locations looking for materials.

\subsection{Proposition 2: the use of AMLTT improves the transactional visibility of materials through information sharing in the construction supply- chain network}

The potential of AMLTT to enhance visibility in the construction supply chain was identified by Young et al. (2011). However, the data from the current study indicate that AMLTT use does not guarantee visibility. Visibility is possible through information shared using AMLTT. Also, the visibility enabled through AMLTT is the transactional visibility of materials. For instance, Song et al. (2004) found that AMLTT allows near-real-time information (status and location) exchange in electronic format between supply-chain participants. Purchase orders, shipments, packing lists, inspections, fabrication progress, material receipts, material storage and location, material withdrawal requests, material pick lists and material issue lists were some of the transactional-level information exchanged at the different supplychain nodes depending on the deployment of the AMLTT system.

A suitable case to support this notion is project P3. The complexity of the supply chain was a unique attribute that led to the implementation of AMLTT in project P3. The owner identified the challenge to maintain the logistics and to ensure timely and accurate delivery of materials to support the module programme. The module programme was part of the critical path of the schedule, and the advanced identification of constraints in the supply chain was vital to the success of the programme. Furthermore, the EPC firm was new to the regulations and procedures since it was a novice in the Canadian market. The owner recognised this risk, particularly combined with high labour rates, and mandated the use of AMLTT from the start of the project. The system improved asset visibility by providing near-real-time status and location information of materials at the different supply-chain nodes (loading port in Asia, the port of arrival in Canada, staging yard and modular project yard) depending on the deployment of the AMLTT system. The supply- chain manager described improved transactional visibility due to AMLTT.

The system provides visibility at the material level. The owner was satisfied as each piece gave the status of individual progress (fabrication, shipping, receipt, issue) from off-site facilities through construction. The detailed level of information about material transactions could even be rolled up to the summary level. The improved visibility also enabled to track if work packages met the schedule evaluating the risk of each work package.

Another example is project P5, where there was $100 \%$ utilisation of AMLTT at the fabrication laydown yard and off-site project laydown yards since there was limited space for inventory storage at the construction job site. The lack of space in the on-site laydown yards required a near-just-in-time process to be followed for the project. The visibility (tracking information) of spools from fabrication to off-site project laydown yards and inventory visibility (status information) at the off-site project laydown yards were critical for meeting the installation schedule. The operations manager described how visibility helped to make site operations more efficient.

The information regarding materials shared using the AMLTT system helped in keeping the off-site and on-site operations at sync based on the construction sequence. There was not enough space on-site for materials, and the material delivery operation was very tight; getting the spools in flatbeds, less space to park, and quick turnaround times meant materials needed to be delivered in a 'just in time' fashion. The additional visibility and control due to the system enormously helped to ease the delivery and installation process.

\subsection{Proposition 3: the use of AMLTT requires a thorough data management plan}

Data management and integration issues, particularly with existing technology, have been highlighted by the broader ICT in the construction literature (Kang et al., 2012). All the seven projects encountered data integration and data management challenges between the AMLTT system and the legacy system (contractor's procurement system). This can be attributed to the temporary and fragmented nature of construction projects; every project is unique and has a unique supply chain (Azambuja and O'Brien, 2009). Also, there is a lack of standardisation and consistency of material information across the material life cycle.

An example of a separate AMLTT and in-house procurement system was that of project P1. The contractor of the project was implementing the AMLTT system for the first time and hence kept the two systems separate. However, the procurement system had to be updated manually every time based on the transactional-level data captured by the AMLTT system. Therefore, keeping the two systems disparate was inefficient and required additional time and resources. On the other hand, the integration of the AMLTT system and the inhouse procurement system was also a challenge on the other six projects. An example of data integration and management is the previously described project $\mathrm{P} 3$. There were many interface points 
between the different stakeholders due to the complexity of the supply chain. It was a significant challenge to understand the data requirements and data transformation requirements from the various stakeholders and their corresponding system into the receiving AMLTT system. For example, some materials had multiple suppliers and sub-suppliers. Every contractor/supplier has its data structure and levels, and integration requires specific customisation. Also, there is no guarantee of the quality of the data from the different contractor and supplier systems. In other cases, engineering/design models would be used to generate unique components and identification numbers. Furthermore, the bill of material data is enormous and critical. All these factors contribute to the significant amount of time and effort required to integrate the two systems on the project. The supply-chain manager of project P3 emphasised the issue.

Significant time and effort were required for background programming to integrate the RFID system and the in-house procurement tool. This will happen in every project because each project is different.

Everyone has their way of coding materials; they have their own systems. These factors need to be accounted for while implementing the system. It frustrated the crew on the project initially and made them doubt the system and loose interest too.

\subsection{Proposition 4: to achieve strategic benefits, the use of AMLTT has to take into account the organisational aspects of AMLTT adoption in projects}

The organisational and sociological challenge associated with ICT implementation in construction has been reported by various studies (Kang et al., 2012; O'Brien, 2000). The AMLTT champions in some of the projects have witnessed reluctance among the upper management and hesitance of the crews in the field to embrace the technology.

The primary factors for resistance by upper management were the cost of implementing the technology and the unclear benefits of AMLTT use. An example of a lack of top-level commitment comes from project P1. The upper management, in this case, was reluctant to invest in the AMLTT system due to its novelty and upfront cost. The materials manager who championed the system on the project had to spend 6 months convincing the top management. He developed a business case to prove savings that can be expected due to process improvement using RFID technology. Once the benefits were realised, the company rolled out the AMLTT system on subsequent projects. Another example of reluctance displayed by the organisations participating in the AMLTT system programme was observed in project P3. The modular programme of the project required close coordination of fabricators, logistic providers, module assembly contractors and EPC. The supply-chain manager described the compliance issue of fabricators and suppliers.

There was hesitance from the EPC to change from legacy system to RFID-based materials management system. The off-site supply chain participants (fabricators, logistic providers, modular yard contractors) also did not comply with the new technology process requirements. But the owner put the clause in the contract. This helped address these issues.

Resistance to change and lack of experience with technology were the major factors of hesitance to the AMLTT system at the field materials management crew level. Project P6 is an example of an organisational challenge due to the field materials management crew. The foreman on the project had an old school of thought regarding technology in general. Consequently, the crewmembers working under him were less motivated to adopt the AMLTT system for their respective work processes. Ultimately, the project manager of the EPC replaced the technology-averse foreman with a 'tech-savvy' foreman, which resulted in the smooth working of the AMLTT system. Project P4 and P5 also faced similar issues with crewmembers entering the material information in the system as a data entry exercise. The operations manager of project $\mathrm{P} 4$ described the situation.

The culture change was the biggest hurdle that had to be tackled. Majority of the crew were used to performing work the old-fashioned way using pen and paper. The crew complained the system slowed them down and would go back to finding materials using the conventional grid and flagging method. Field personnel would find the materials in the old-fashioned way and enter the data into the materials management system just to comply with the process.

\section{Discussion}

The operational use of AMLTT in industrial construction projects has developed in the past decade. In particular, communication networks, sensors and mobile devices have increased the possibilities of networking with supply chain partners. The extant literature in construction posits that AMLTT improves visibility in the supply-chain network. The result of the current study indicates that AMLTT does not automatically provide visibility. It depends on the scope of implementation of AMLTT and the quality of information that is exchanged using the AMLTT system. Thus, visibility is enabled by information sharing and does not depend on the AMLTT itself. Also, the visibility enabled through AMLTT is the transactional visibility of materials at the operational level. This is in line with the broader business literature on visibility (Barratt and Oke, 2007; Nassar, 2011). As per Barratt and Oke (2007), information sharing is the activity and visibility is an outcome of the activity.

Furthermore, based on the AMLTTs and capabilities of the investigated projects, it can be inferred that the industrial construction industry has been slow in keeping pace with recent advancements in digitisation. This is in line with a study by McKinsey \& Company (Agarwal and Sridhar, 2016), which found that the construction industry was among the least digitised industries (just above agriculture and hunting). For instance, the idea of CPSs and DTs was not even conceptualised in any of the investigated projects. The supply-chain manager of project 3 did develop a simulation model for tactical planning purposes at the 
start of the project. However, the model did not have the capability to be updated and monitored as per the execution of the project.

The current study indicates that AMLTT improves operational efficiency. This finding is in line with the broader literature on information technology (IT) adoption in the supply chain (Min and Galle, 2001; SCC, 2002; Sohal et al., 2002). All these studies reported that the adoption of IT enhances the efficiency of supplychain management. Furthermore, the extant literature posits that AMLTT use improves productivity (Grau et al., 2009). The current study extends this finding and shows that productivity improvement due to AMLTT use allows the crew and/or firm to focus on business-critical activities.

Table 4 shows in detail if the specific benefits and challenges observed are linked to the extant literature and the seven investigated cases. As evident from the Table 4, there is limited literature on AMLTT challenges concerning the industrial construction sector. Interestingly, the data integration and management challenge of AMLTT that was observed across all the investigated projects in the current study was not discovered in any of the extant literature on AMLTT. This can be attributed to the small-scale deployments studied earlier that do not entail large volumes of data. The other exception observed in the current study and not found in literature is the lack of knowledge about the benefits of AMLTT. Limited evidence of success through case studies performed in real construction projects (Sardroud, 2015) might have contributed to this issue. There are many interface points between the different stakeholders due to the complexity of an industrial supply chain (Shokri et al., 2015). It is essential to understand the data requirements and data transformation requirements from the various stakeholders and their corresponding system into the receiving AMLTT system. Finally, it can be concluded that the identified challenges regarding the ICT of the broader construction industry are generalisable in terms of their applicability to the industrial construction sector. The observed challenges would be a good start for further studies.

A review of the AMLTT benefit references in Table 4 shows that most of the benefits were observed across the investigated cases and have been identified by the existing literature. The exception not found in the literature was improved safety due to AMLTT. A significant amount of work has been done concerning automated monitoring of the location and direction of on-site workers and construction equipment using real-time locating and tracking technologies (Soltanmohammadlou et al., 2019). However, the reduction of the hazard exposure of material-locating crew due to the identification and locating of construction materials using AMLTT warrants future research. The exception that was identified in the literature but not across the case studies was less reliance on material buffers. The majority of the projects investigated had materials procured well in advance of the installation schedule and years of inventory in laydown yards/ warehouses. This is the typical strategy employed by materials
Table 4. Links between literature review and case findings

\begin{tabular}{|c|c|c|}
\hline $\begin{array}{l}\text { Benefits and } \\
\text { challenges of } \\
\text { AMLTT (expected } \\
\text { and observed) }\end{array}$ & Literature source & $\begin{array}{l}\text { Case } \\
\text { study } \\
\text { finding }\end{array}$ \\
\hline \multicolumn{3}{|l|}{ Benefits } \\
\hline $\begin{array}{l}\text { Reduces operation } \\
\text { time/improves schedule }\end{array}$ & $\begin{array}{l}\text { Grau et al. (2012), } \\
\text { Song et al. (2006b), } \\
\text { Young et al. (2011) }\end{array}$ & $\begin{array}{l}\text { P1, P2, P3, } \\
\text { P4, P5, } \\
\text { P6, P7 }\end{array}$ \\
\hline $\begin{array}{l}\text { Accurate and timely } \\
\text { material } \\
\text { information/increases } \\
\text { information sharing }\end{array}$ & Song et al. (2006b) & $\begin{array}{l}\text { P1, P2, P3, } \\
\text { P4, P5, } \\
\text { P6, P7 }\end{array}$ \\
\hline Improves visibility & Young et al. (2011) & $\begin{array}{l}\text { P1, P2, P3, } \\
\text { P4, P5, } \\
\text { P6, P7 }\end{array}$ \\
\hline $\begin{array}{l}\text { Less reliance on } \\
\text { material buffers }\end{array}$ & Young et al. (2011) & \\
\hline $\begin{array}{l}\text { Labour time and } \\
\text { cost savings }\end{array}$ & $\begin{array}{c}\text { Caldas et al. (2006), } \\
\text { Grau et al. (2012) }\end{array}$ & $\begin{array}{l}\text { P1, P2, P3, } \\
\text { P4, P5, } \\
\text { P6, P7 }\end{array}$ \\
\hline $\begin{array}{l}\text { Reduced misplacement and } \\
\text { re-procurement }\end{array}$ & $\begin{array}{l}\text { Caldas et al. (2006), } \\
\text { Grau et al. (2012), } \\
\text { Song et al. (2006b) }\end{array}$ & $\begin{array}{l}\text { P1, P2, P3, } \\
\text { P4, P5, } \\
\text { P6, P7 }\end{array}$ \\
\hline $\begin{array}{l}\text { Process re-engineering/ } \\
\text { improvement }\end{array}$ & $\begin{array}{l}\text { Caldas et al. (2006), } \\
\text { Grau et al. (2009) }\end{array}$ & $\begin{array}{l}\text { P1, P2, P3, } \\
\text { P4, P5, } \\
\text { P6, P7 }\end{array}$ \\
\hline $\begin{array}{l}\text { Craft efficiency/productivity } \\
\text { improvement }\end{array}$ & $\begin{array}{c}\text { Caldas et al. (2006), } \\
\text { Grau et al. (2009) }\end{array}$ & $\begin{array}{l}\text { P1, P2, P3, } \\
\text { P4, P5, } \\
\text { P6, P7 }\end{array}$ \\
\hline $\begin{array}{l}\text { Reduced manual } \\
\text { operation errors }\end{array}$ & Caldas et al. (2006) & $\begin{array}{l}\text { P1, P2, P3, } \\
\text { P4, P5, } \\
\text { P6, P7 }\end{array}$ \\
\hline Optimises logistics & Caldas et al. (2006) & P4, P7 \\
\hline $\begin{array}{l}\text { Enhanced data } \\
\text { entry/reduces error } \\
\text { reporting }\end{array}$ & Caldas et al. (2006) & $\begin{array}{l}\text { P1, P2, P3, } \\
\text { P4, P5, } \\
\text { P6, P7 }\end{array}$ \\
\hline Improves safety & & $\begin{array}{l}\text { P2, P3, P4, } \\
\text { P6 }\end{array}$ \\
\hline \multicolumn{3}{|l|}{ Challenges } \\
\hline Deployment costs & Sardroud (2015) & P1 \\
\hline Technical issues & $\begin{array}{l}\text { Akinci et al. (2004), } \\
\text { Caldas et al. (2004), } \\
\text { Song et al. (2004) }\end{array}$ & P1, P5, P6 \\
\hline Data integration & & $\begin{array}{l}\text { P2, P3, P4, } \\
\text { P5, P6, } \\
\text { P7 }\end{array}$ \\
\hline Data management & & $\begin{array}{l}\text { P1, P2, P3, } \\
\text { P4, P5, } \\
\text { P6, P7 }\end{array}$ \\
\hline Lack of standards & Sardroud (2015) & \\
\hline $\begin{array}{l}\text { Lack of implementation } \\
\text { process knowledge }\end{array}$ & Sardroud (2015) & P1 \\
\hline $\begin{array}{l}\text { Lack of knowledge about } \\
\text { benefits }\end{array}$ & & P1, P7 \\
\hline Maintenance costs & Sardroud (2015) & P1 \\
\hline $\begin{array}{l}\text { Uncertainty of return of } \\
\text { investment }\end{array}$ & Sardroud (2015) & $\begin{array}{l}\text { P1, P3, P5, } \\
\text { P7 }\end{array}$ \\
\hline $\begin{array}{l}\text { Organisational } \\
\text { issues (organisational, } \\
\text { management, } \\
\text { change, people) }\end{array}$ & $\begin{array}{l}\text { Erdogan et al. (2008), } \\
\text { O'Brien (2000) }\end{array}$ & $\begin{array}{l}\text { P1, P3, P4, } \\
\text { P5, P6, } \\
\text { P7 }\end{array}$ \\
\hline
\end{tabular}


managers on construction projects to ensure that a sufficient backlog of materials is available on-site. This buffering strategy cushions the project against uncertainty in off-site production and on-site planning. However, the existing literature claims otherwise. The effect of AMLTT on inventory management would be a good area for future research, particularly now since the industry has more visibility into material deliveries and inventory as a result of AMLTT use.

\section{Conclusions}

This paper contributes to the literature by enhancing understanding of the benefits and challenges regarding AMLTT implementation concerning the industrial construction sector. For the construction industry practitioners, the knowledge of benefits and challenges is expected to improve confidence regarding AMLTT adoption on projects. Technology vendors can use the results to enhance existing or develop new AMLTTs.

In comparison with the independent field experiments using technology prototypes conducted previously, this study investigated multiple in-depth cases that represented different projects and the scope of AMLTT implementation. However, the study has some limitations. First, the sample of projects is biased towards companies willing to discuss and share results openly. Second, the generalisation of the findings to all kinds of technology within AMLTT should be made with caution since some of the observed benefits and challenges might not apply to all technologies within AMLTT. Nevertheless, the findings can be extended to a greater population of projects within the industrial sector. Future work should include more case studies spanning various project types to substantiate the lessons learned. More case studies will also improve the knowledge regarding the benefits and challenges of AMLTT implementation.

The findings provide areas for future research. An immediate next step for the study is to test the four suggested propositions with a larger data set to gain further understanding of the various possibilities (supply chain type, the technology used etc.). Second, the EPC championed the AMLTT system in projects with lumpsum agreement between the EPC and the owner, while the costplus/cost-reimbursable contracts had the owner championing the system in the project. Although there seems to be a trend in contract type and technology adoption, further research is required to establish a definite proposition. Past studies in construction have regularly used the expression of construction supply chain visibility and highlighted its importance. However, it is a relatively under-researched area in the construction industry compared with the supply-chain management and logistics community. The authors suggest more research in the area of construction supply chain visibility, particularly focusing on the data/information exchange needed for improving visibility. Such a study will also serve as a starting point for the data integration and data management issues that were revealed in the current study. Finally, more focused research on the challenges to AMLTT implementation in industrial construction is required.

\section{Acknowledgements}

The authors would like to acknowledge Fully Integrated and Automated Technology (Fiatech), an industry-funded research consortium to promote the development and adoption of innovative technologies for the capital projects industry, for funding this research. The authors are also grateful to the firms and the case study interviewees that participated in the study.

\section{Appendix: Case study questions}

(a) Could you please describe your title/position and primary responsibilities?

(b) To which category (owner, contractor/EPC [engineering-procurement-construction], supplier/vendor) does your company belong?

(c) Please describe the project and its supply chain

(i) subsector (oil and gas, power, pharmaceutical etc.)

(ii) type of project site (greenfield, brownfield, renovation etc.)

(iii) project delivery type (EPC, construction manager at risk, engineering procurement - construction management, owner-managed etc.)

(iv) construction contract type (lump-sum, unit-price, costreimbursable)

(v) location (developed country, developing country, remote location etc.)

(vi) size (amount of work, number of prime general contractors and amount of materials to be managed)

(vii) space (laydown/warehouse space)

(viii) logistics (national, international suppliers etc.)

(ix) project driver (cost, schedule)

(x) baseline project cost (TIC [total installed cost]) and actual project cost (TIC)

(xi) baseline project duration and actual duration.

(d) The current phase of the project? Was the project fast-tracked? Was the fast-tracking due to materials management issues?

(e) What tools/software was used for automated identification, locating and tracking of construction materials in the supply chain and on the project site? And for what materials? Which project participant's processes did the tool communicate with? Could you please provide a demonstration of the tool/ software?

(f) Why were the tools/software for automated identification, locating and tracking implemented on the project?

$(g)$ How were the tools/software for automated identification, locating and tracking implemented on the project? Could you please describe the process and provide examples where possible?

(h) How was the data/information exchange across the material supply chain on the project using the tool/software? Can you provide some examples of screenshots of what data/ information you were tracking? 
(i) Please describe the benefits the project has experienced from automated identification, locating and tracking tool/software.

(j) Please describe any challenges the project experienced during the implementation of automated identification, locating and tracking tool/software. What were the specific conditions that led to them?

\section{REFERENCES}

Agarwal R and Sridhar M (2016) Imagining Construction's Digital Future. McKinsey Productivity Sciences Center, McKinsey \& Company, Singapore.

Akinci B, Ergen E, Haas C et al. (2004) Field Trials of RFID Technology for Tracking Fabricated Pipe. Smart Chips Project, Fiatech, Austin, TX, USA.

Aksoy J, Chan I, Guidry K, Jones J and Wood C (2004) Materials and Asset Tracking Using RFID: a Preparatory Field Pilot Study. Smart Chips Project, Fiatech, Austin, TX, USA.

Anumba CJ, Akanmu A and Messner J (2010) Towards a cyber-physical systems approach to construction. In Construction Research Congress 2010: Innovation for Reshaping Construction Practice (Ruwanpura J, Mohamed Y and Lee S (eds)). American Society of Civil Engineers, Reston, VA, USA, pp. 528-537.

Azambuja M and O'Brien WJ (2009) Construction supply chain modeling: issues and perspectives. In Construction Supply Chain Management Handbook (O’Brien WJ, Formoso CT, Ruben V and London K (eds)). CRC Press, Boca Raton, FL, USA, pp. 2.1-2.31.

Barratt M and Oke A (2007) Antecedents of supply chain visibility in retail supply chains: a resource-based theory perspective. Journal of Operations Management 25(6): 1217-1233, https://doi.org/10.1016/j. jom.2007.01.003.

Bell LC and McCullouch BG (1988) Bar code applications in construction. Journal of Construction Engineering and Management 114(2): 263-278, https://doi.org/10.1061/(ASCE)0733-9364(1988)114:2(263).

Bell LC and Stukhart G (1987) Costs and benefits of materials management systems. Journal of Construction Engineering and Management 113(2): 222-234, https://doi.org/10.1061/(ASCE)07339364(1987)113:2(222).

Caldas C, Haas C, Grau D, Wood CR and Porter R (2004) Field Trials of GPS Technology for Locating Fabricated Pipe in Laydown Yards. Fiatech, Austin, TX, USA

Caldas C, Torrent D and Haas C (2006) Using global positioning system to improve materials-locating processes on industrial projects. Journal of Construction Engineering and Management 132(7): 741-749, https:// doi.org/10.1061/(ASCE)0733-9364(2006)132:7(741).

CII (Construction Industry Institute) (1988) Project Materials Management Handbook. The University of Texas at Austin, Austin, TX, USA.

Eisenhardt KM (1989) Building theories from case study research. Academy of Management Review 14(4): 532-550, https://doi.org/10. 5465/amr.1989.4308385.

Erdogan B, Anumba CJ, Bouchlaghem D and Nielsen Y (2008) Collaboration environments for construction: implementation case studies. Journal of Management in Engineering 24(4): 234-244, https://doi.org/10.1061/(ASCE)0742-597X(2008)24:4(234).

Ergen E, Akinci B and Sacks R (2007) Life-cycle data management of engineered-to-order components using radio frequency identification. Advanced Engineering Informatics 21(4): 356-366, https://doi.org/10. 1016/j.aei.2006.09.004

Grau D, Caldas CH, Haas CT, Goodrum PM and Gong J (2009) Assessing the impact of materials tracking technologies on construction craft productivity. Automation in Construction 18(7): 903-911, https://doi. org/10.1016/j.autcon.2009.04.001.

Grau D, Zeng L and Xiao Y (2012) Automatically tracking engineered components through shipping and receiving processes with passive identification technologies. Automation in Construction 28: 36-44, https://doi.org/10.1016/j.autcon.2012.05.016.

Irizarry J and Costa DB (2016) Exploratory study of potential applications of unmanned aerial systems for construction management tasks. Journal of Management in Engineering 32(3): article 05016001, https://doi.org/10.1061/(ASCE)ME.1943-5479.0000422.

Jaselskis EJ and El-Misalami T (2003) Implementing radio frequency identification in the construction process. Journal of Construction Engineering and Management 129(6): 680-688, https://doi.org/10. 1061/(ASCE)0733-9364(2003)129:6(680).

Jaselskis EJ, Anderson MR, Jahren CT, Rodriguez Y and Njos S (1995) Radio-frequency identification applications in construction industry. Journal of Construction Engineering and Management 121(2): 189-196, https://doi.org/10.1061/(ASCE)0733-9364(1995)121:2(189).

Kaming P, Holt G and Kometa S (1998) Severity diagnosis of productivity problems - a reliability analysis. International Journal of Project Management 16(2): 107-113, https://doi.org/10.1016/S0263-7863(97) 00036-7.

Kan C and Anumba CJ (2019) Digital twins as the next phase of cyberphysical systems in construction. In Computing in Civil Engineering 2019: Data, Sensing, and Analytics (Cho YK, Leite F, Behzadan A and Wang C (eds)). American Society of Civil Engineers, Reston, VA, USA, pp. 256-264.

Kang Y, O'Brien WJ and O'Connor JT (2012) Analysis of information integration benefit drivers and implementation hindrances. Automation in Construction 22: 277-289, https://doi.org/10.1016/j.autcon.2011.09. 003.

Kerridge AE (1987) Manage materials effectively. Hydrocarbon Processing, May: pp. 63-71.

Ko HS, Azambuja M and Lee HF (2016) Cloud-based materials tracking system prototype integrated with radio frequency identification tagging technology. Automation in Construction 63: 144-154, https:/doi.org/ 10.1016/j.autcon.2015.12.011

Li N and Becerik-Gerber B (2011) Life-cycle approach for implementing RFID technology in construction: learning from academic and industry use cases. Journal of Construction Engineering and Management 137(12): 1089-1098, https://doi.org/10.1061/(ASCE)CO.1943-7862. 0000376.

Li H, Chan G, Wong JKW and Skitmore M (2016) Real-time locating systems applications in construction. Automation in Construction 63(Supplement C): 37-47, https://doi.org/10.1016/j.autcon.2015.12.001. Lincoln YS and Guba EG (1985) Naturalistic Inquiry. Sage, London, UK.

Min H and Galle WP (2001) Electronic commerce-based purchasing: a survey on the perceptual differences between large and small organisations. International Journal of Logistics 4(1): 79-95, https:// doi.org/10.1080/13675560110038086.

Nassar S (2011) Supply Chain Visibility and Sustainable Competitive Advantage: an Integrated Model. $\mathrm{PhD}$ thesis, University of Bath, Bath, UK.

O'Brien WJ (2000) Implementation issues in project web sites: a practitioner's viewpoint. Journal of Management in Engineering 16(3): 34-39, https://doi.org/10.1061/(ASCE)0742-597X(2000)16:3(34).

Rasdorf WJ and Herbert MJ (1990) Bar coding in construction engineering. Journal of Construction Engineering and Management 116(2): 261-280, https://doi.org/10.1061/(ASCE)0733-9364(1990) 116:2(261).

Razavi SN and Haas CT (2011) Using reference RFID tags for calibrating the estimated locations of construction materials. Automation in Construction 20(6): 677-685, https://doi.org/10.1016/j.autcon.2010.12.009.

Sardroud JM (2015) Perceptions of automated data collection technology use in the construction industry. Journal of Civil Engineering and Management 21(1): 54-66, https://doi.org/10.3846/13923730.2013. 802734.

SCC (Supply-Chain Council) (2002) E-Business and Supply Chain Processes. SCC, Pittsburgh, PA, USA. 
Smart Infrastructure and Construction

Volume 171 Issue 4
Benefits and challenges of automated

materials technology in industrial

construction projects

Dharmapalan and O'Brien
Shokri S, Haas CT, Haas RC and Lee SH (2015) Interface-management process for managing risks in complex capital projects. Journal of Construction Engineering and Management 142(2): 1-12, https://doi. org/10.1061/(ASCE)CO.1943-7862.0000990.

Slaughter SA, Levine L, Ramesh L, Pries-Heje J and Baskerville R (2006) Aligning software processes with strategy. MIS Quarterly 30(4): 891-918.

Sohal AS, Power DJ and Terziovski M (2002) Supply chain management in Australian manufacturing - two case studies. Computers \& Industrial Engineering 43(1-2): 97-109, https://doi.org/10.1016/S0360-8352(02) 00069-4.

Soltanmohammadlou N, Sadeghi S, Hon CK and Mokhtarpour-Khanghah F (2019) Real-time locating systems and safety in construction sites: a literature review. Safety Science 117: 229-242, https://doi.org/10 1016/j.ssci.2019.04.025.

Song J, Haas C, Caldas C et al. (2004) Field Trials of RFID Technology for Tracking Fabricated Pipe - Phase 2. Smart Chips Project, Fiatech, Austin, TX, USA.

Song J, Haas C and Caldas C (2006a) Tracking the location of materials on construction job sites. Journal of Construction Engineering and Management 132(9): 911-918, https://doi.org/10.1061/(ASCE)07339364(2006)132:9(911).

Song J, Haas CT, Caldas C, Ergen E and Akinci B (2006b) Automating the task of tracking the delivery and receipt of fabricated pipe spools in industrial projects. Automation in Construction 15(2): 166-177, https://doi.org/10.1016/j.autcon.2005.03.0
Stukhart G and Bell L (1986) Attributes of materials management systems. Journal of Construction Engineering and Management 112(1): 14-21, https://doi.org/10.1061/(ASCE)0733-9364(1986)112:1(14).

Thomas HR, Riley DR and Messner JI (2005) Fundamental principles of site material management. Journal of Construction Engineering and Management 131(7): 808-815, https://doi.org/10.1061/(ASCE)07339364(2005)131:7(808).

Torrent D and Caldas C (2009) Methodology for automating the identification and localization of construction components on industrial projects. Journal of Computing in Civil Engineering 23(1): 3-13, https://doi.org/10.1061/(ASCE)0887-3801(2009)23:1(3).

Valero E and Adán A (2016) Integration of RFID with other technologies in construction. Measurement 94: 614-620, https://doi.org/10.1016/j. measurement.2016.08.037.

Vorster M and Lucko g (2002) Construction technology needs assessment update. Construction Industry Institute, The University of Texas at Austin, Austin, TX, USA.

Wood C and Alvarez M (2005) Emerging Construction Technologies - a Fiatech Catalogue. Fiatech, Austin, TX, USA.

Yin R (2009) Case Study Research. Sage, Thousand Oaks, CA, USA, vol. 5 .

Young D, Haas C, Goodrum P and Caldas C (2011) Improving construction supply network visibility by using automated materials locating and tracking technology. Journal of Construction Engineering and Management 137(11): 976-984, https://doi.org/10.1061/(ASCE) CO.1943-7862.0000364

\section{How can you contribute?}

To discuss this paper, please email up to 500 words to the editor at journals@ice.org.uk. Your contribution will be forwarded to the author(s) for a reply and, if considered appropriate by the editorial board, it will be published as discussion in a future issue of the journal.

Proceedings journals rely entirely on contributions from the civil engineering profession (and allied disciplines). Information about how to submit your paper online is available at www.icevirtuallibrary.com/page/authors, where you will also find detailed author guidelines. 